\title{
Noms d'aurigues i de gladiadors en dos peces de vidre d’Empúries *
}

\author{
Marta Darder G-Z-Lisson **
}

Actualment en el Museu Arqueològic de Barcelona es conserven dos fragments vitris amb inscripció i imatge circenca trobats a Empúries ${ }^{1}$. Al Museu Monogràfic d'Empúries ${ }^{2}$ hi trobem un altre fragment, que s'uneix, completant en part la inscripció, a un dels dos anteriors.

És desconegut tot tipus d'informació sobre la troballa i context arqueològic d'aquestes tres peces. La base més sòlida de documentació per a datar i classificar aquest material ens la donen els paral.lels vitris romans trobats en la resta del que fou el terreny de l'Imperi ${ }^{3}$.

Els dos primers fragments que estudiarem formen part d'un mateix vas en vidre de color verd oliva de tipus tronco-cònic sortit d'un motlle (fig. 1a i b) ${ }^{4}$. El més possible és que ambdos fragments formessin part d'un vas.

* Per al Dr. E. Ripoll i Perelló, amb estima i per l'estima.

* Universitat Autònoma de Barcelona.

' M. Almagro, Las inscripciones ampuritanas griegas, ibéricas y latinas, Barcelona, 1952, n. 155 i 156. I més recentment D.B. HaRDEN publicà el $n .155$ a: "New light on moldblown glass sports cup on the first century A.D. bearing both chariot races in bigae and gladiatorial combats" Journal of Glass Studies, 24, (Corning - New York) 1982, págs. 3940, n. 7 , fig. 9.

2 AlmAGRO, op. cit. 1952, n. 153. També per a la bibliografia anterior.

${ }^{3}$ Sobre vidres a l'Imperi, entre d'altres: A. KISA, Das Glass im Altertum, Leipzig, 1908, sobretot vol. II-III; D.B. HARDEN, Glass of the Caesars, Milà, 1987 (Catàleg de l'exposició 2011-1987 / 6-3-1988) i MORIN-JEAN, La verrerie en Gaule sous l'Empire Romain, Nogent-le-Roi, 1977; d'aquest darrer és interessant la tipologia que estableix dels diferents tipus de vidres.

4 Almagro, op. cit., 1952, n. 153 i 156. La part del n. 156 que sembla perduda, és la que el mateix Almagro publica en la pàgina anterior com un altre fragment isolat. El color, la forma tant tipologica com la forma en que estan fragmentats, i la inscripció es corresponen exactament un amb l'altre (cf. figura 1 i 2 ). 
el relleu del qual es distribuis en tres registres. En les peces hi trobem els dos registres de la part alta del vas; en el superior hi ha la inscripció amb les lletres majúscules en un suau però clar relleu ${ }^{5}$. Es pot dir que originàriament hi havia quatre noms seguits de la formula VA que donaven la volta a tot el vas. En els nostres fragments només hi podem veure /]NCITATEVA I, en el fragment conservat a Barcelona, I]CAREYA, en el fragment d'Empúries que segueix al de Barcelona. La inscripció queda INCITATEVA ICA$R E V A$. En el registre de la spina, el central, només es veu -de dreta a esquerra- l'obelisc, un felí (el lleó de Cíbeles?) sobre un pedestal, una de les metae, un pedestal i el començament d'una figura.

L'altre fragment conservat a Barcelona és del mateix material, textura i color que els altres dos i possiblement hagi sortit del mateix taller de producció ${ }^{6}$. La forma cóncava ens fa pensar en peces semblants (algunes recollides en les figures 4 i 5) on també hi ha representacions de gladiadors. Es difícil, però, donat el petit tamany del fragment, determinar a quin tipus de peça pertanyia. És gairebé descartable que formés part del vas anterior. El que si es pot dir, mirant els paral-lels, és que formava part d'un utensili que tenia com a minim, i potser únicament, dos registres.

En la part superior d'aquest fragment hi ha la resta de quatre potes de cavalls, una biga - el més segur- 0 un quadriga. Sota la franja que divideix el fragment en dos registres hi ha la inscripció: -]MES FAOR[-. Almagro i Piernavieja ${ }^{7}$ llegeixen $A E S$ com a nom sencer; la $M$ i la $E$ formen un nexe, la $E$ es recolça del tot en l'últim tram vertical de la $M$, però en diagonal doncs és una $\mathrm{M}$ molt oberta. Sota les tres primeres lietres hi ha un relleu en forma d'ou en posició horitzontal que fa pensar en un escut o qualsevol altre estri utilitzat pels gladiadors en l'amfiteatre. A l'esquerra de les últimes lletres també hi ha el començament d'algun relleu, indicis de l'existència de figures humanes, lluitadors - sota o al costat- de la inscripció. Aquest fet també concorda amb els paral.lels existents, com per exemple el de Southwark (Londres) (fig. 6.1), Harlip

El fragment d'Incitatus (fig. 1 i 2.3.) medeix $6 \mathrm{~cm}$. de diàmetre de boca i $5 \mathrm{~cm}$. d'alçada màxima. El fragment de Faor (fig. 3) mesura d'amplada $5 \mathrm{~cm}$. i $2,4 \mathrm{~cm}$. d'amplada. Agraïm la gentilesa per les facilitats donades al Museu Arqueològic de Barcelona i especialment la gran ajuda i informació que ens ha transmés la conservadora de dit museu, na Teresa Carreras. Un article d'ella mateixa i de'n P. Villalba, publicat en aquest mateix volum, dóna una visió contextual més amplia d'aquests dos fragments entre els vidres catalans.

${ }^{6}$ La forma d'aquest vas es pot identificar -encara que no s'assembli exactamentamb el n. 83 de la classificació feta per Morin-Jean, op. cit., 1977, pág. 189 i ss. i pág. 127 per la descripció de la forma.

7 Almagro, op. cit., n. 155 i Piernavieja, Corpus de inscripciones deportivas de España Romana, Madrid, 1972, págs. 96-97 i n. 1 i 12. HARDEN, op. cit., 1982, pág. 39, ja llegeix .. - MES. 

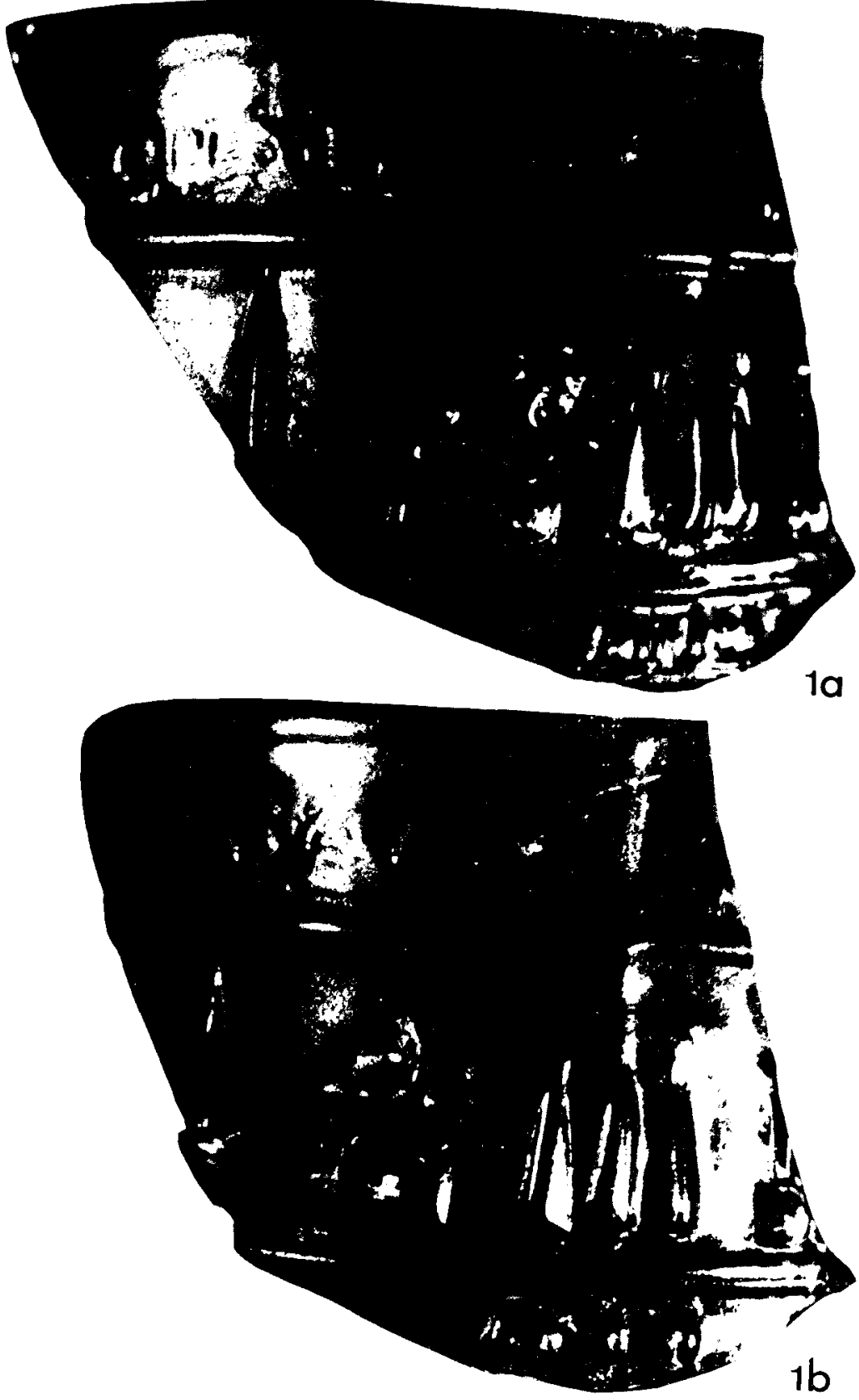

Fig. 1. Fragment d'un vidre trobat a Empúries (Girona). (Fotografies: M.A.B.). 
(Kent) (Fig 6.2) o com el de Oberwinterthur (Viturum, Suïssa) (fig. 6.3).

La qüestió més important a resoldre i que porta i ha portat més divergències entre els estudiosos ha estat el determinar i esbrinar si els noms inscrits en aquests vidres es referien als gladiadors, als aurigues 0 als cavalls representats, encara que fossin recordatoris en forma simbolica de vencedors i herois circencs o d'amfiteatre.

En els primers fragments (fig. 1 i 2 ) el dubte ha estat entre si eren els noms del funalis de l'esquerra - el cavall que duia tota la carrega del carro a l'hora de tombar en cada metae - de cada quadriga o si eren els noms dels aurigues.

En el petit fragment (fig. 3), on hi ha les potes de cavall just a sobre - i en registre diferent- de la inscripció, llegim: HER]MES FA(v)OR[. Almagro i Piernavieja els posaren com a noms de cavalls. Harden i Ville entre d'altres ja els classifiquen com a noms de gladiadors ${ }^{8}$.

Per l'estudi comparatiu amb altres fragments vitris més complerts pràcticament idèntics al que ens ocupa (fig. 5), a més dels paral-lels onomàstics en altres fonts documentals romanes que ens donen noms de gladiadors semblants a aquests, HERMES i FAOR són noms de gladiadors.

No hi ha cap cavall amb aquests noms. Els noms mitològics o referits a herois que duen els cavalls circencs estan relacionats amb fenòmens astrals, com HELIOS ${ }^{9}$, URANIUS ${ }^{10}$, etc..., o són noms que es relacionen directament amb qualitats dels equi, com PEGASUS ${ }^{11}$, $P E L O P S^{12}$ fundador dels jocs olímpics, entre d'altres, encara que també trobem noms com PHOEBUS ${ }^{13}$, TITAS $^{14}$, etcètera.

" Per aquest fragment l'article de G. VILLE, "Les coupes de Trimalcion figurant des gladiateurs et une série de verres "sigillés" gaulois", Hommages à Jean Bayet, (Latomus) 1964, pags. $721-733$, recull gran varietat de vasos de vidre amb representacions figurades i onomàstiques de gladiadors; amb un estudi molt complert de dits noms, on és molt freqüent el d'Hermes. HaRden, op. cit., 1982, pág. 39, també el cita com a nom de gladiador.

${ }^{9}$ Nom testimoniat varies vegades en una defixio de Susa: A. Audollent, Defixionum tabellae.... Paris, 1903, n. 276 (1. 7) págs. 385-386; en una inscripció de Roma (C/L VI 10053); etcètera.

${ }^{10}$ Uranius també el trobem en una peça d'ivori de Roma del s. IV d.C.: Ch. PICARD, "Chevaux de course et aurigues vainqueurs", Rev. Arq., XXXV. (1950) p. 199.

"Pegasus és testimoniat tant en inscripcions sobretot a Roma (C/L VI 37834, col. b. 1.6), com en un contorniat de la Renania: M. Bos, "Spielsteine als Rennpferde", Bonner Jahrbücher des Rheinischen Landesmuseum in Bonn, 155-156 (1955-56), pág. 181, fig. 2; o en un mosaic de Sorothus de Susa.

${ }_{12}$ Pelops, un testimoni conegut per dues vegades a la Península: : en el mosaic circenc de Barcelona i en el de Torre de Palma. També el trobem en defixiones de Susa.

El trobem en defixiones de Roma (AUdOLlent, op. cit., n. 160, ...).

Titas de Tita(n)s, com Cresces de Cresce(n)s, surt en el mosaic de Oued-Athmenia 

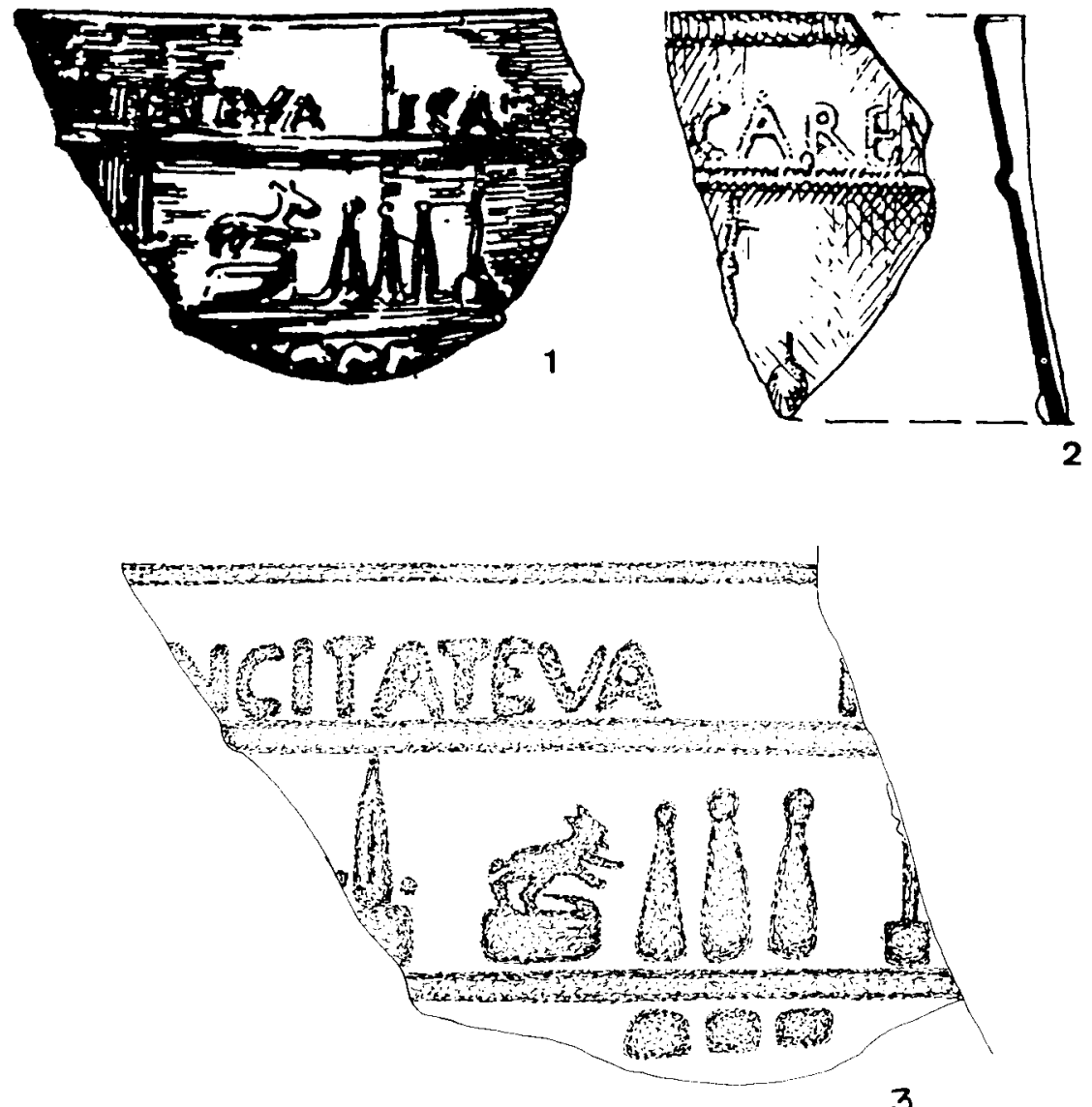

Fig. 2. 1, Empúries (segons M. Almagro, n. 153, 1952); 2, Empúries (segons $M$. Almagro, n. 156, 1952); 3, decoració del vidre d'Empúries (segons nosaltres, dibuix N. Arranz). 

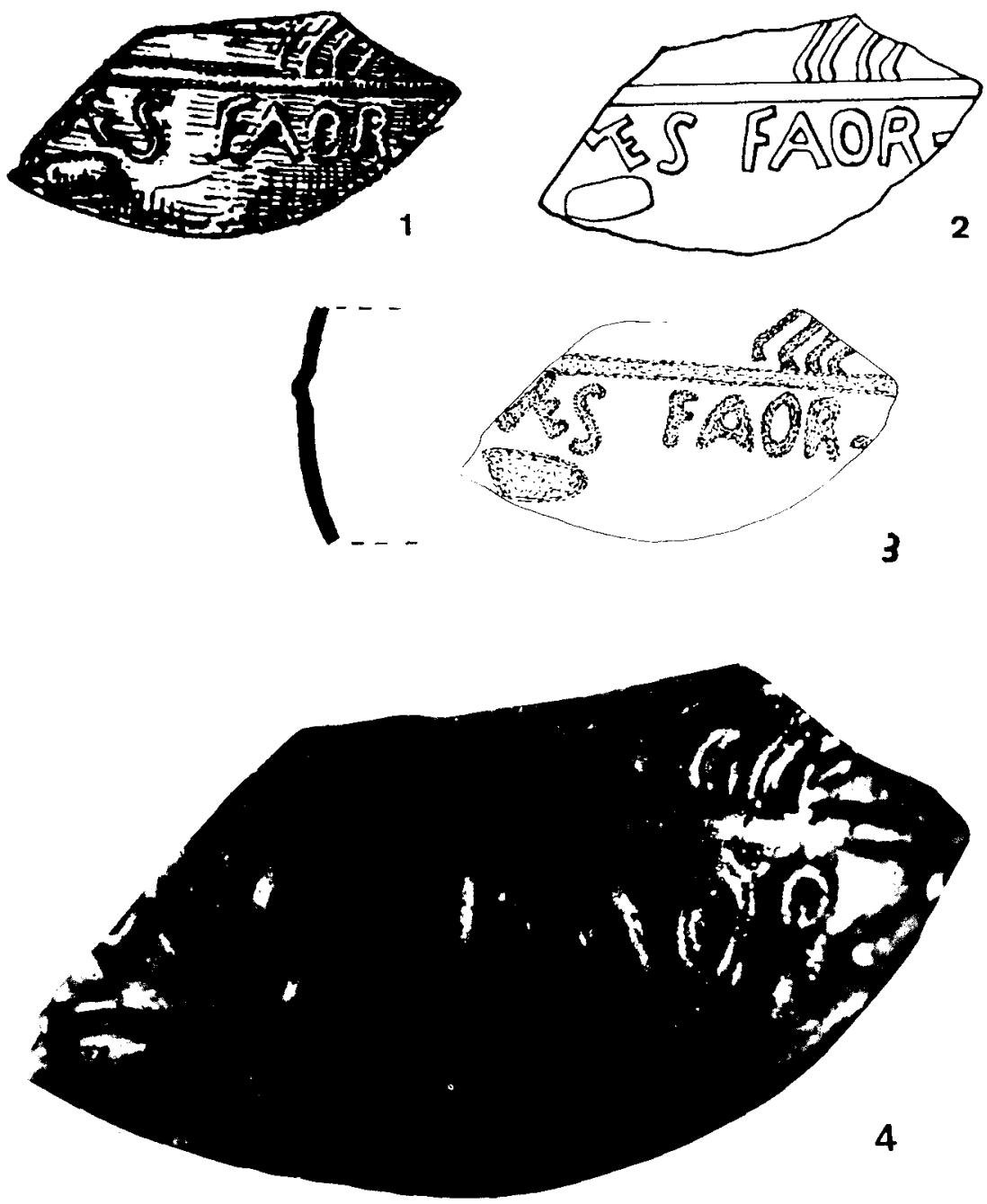

Fig. 3. Fragment de vidre d'Empúries. 1, segons M. Almagro, n. 155, 1952; 2, segons D. B. Harden, 1982; 3, nostra interpetació (dibuix N. Arranz); 4, fotografía del fragment (M.A.B.). 


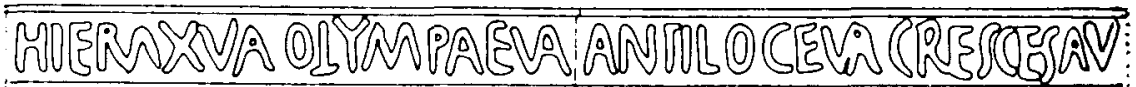
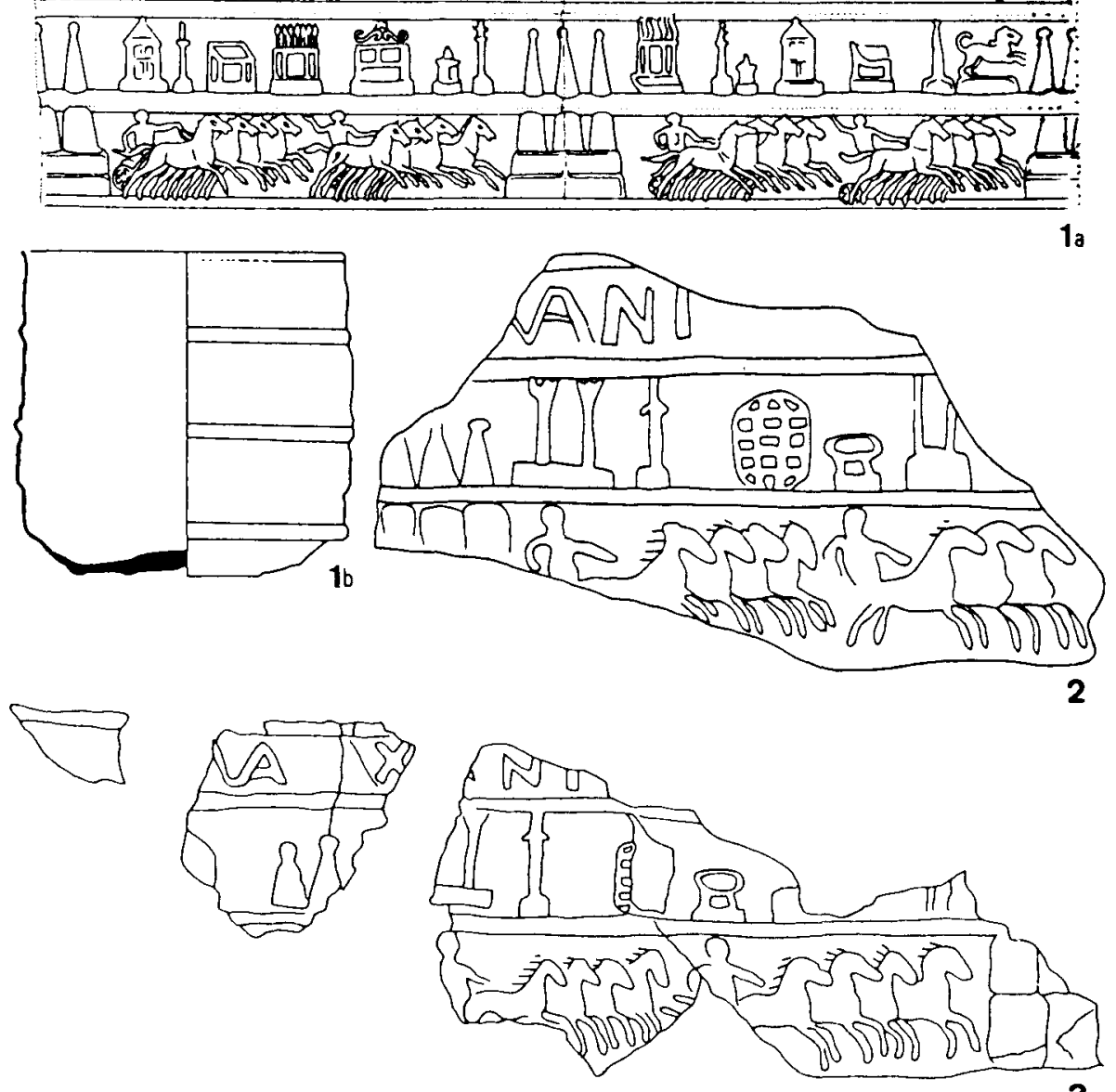

Fig. 4. 1a-1b, Colchester (British Museum) (segons D.B. Harden, 1987); 2, Orange (Museu de Nimes); 3, Tunis (Museu de Leyde); $(2$ i 3, segons J.H.C. Kern, 1954). 
El nom d'HERMES s'apropa més a la força, la intrepidesa i l'astúcia, qualitats més pròpies d'un hàbil gladiador que no pas d'un cavall de cursa. A més, el trobem testimoniat vàries vegades com a nom de gladiador, per exemple en un vas de vidre groc transparent conservat integre, actualment al Metropolitan Museum de Nova York ${ }^{15}$.

FAOR es podria interpretar com Fa(v)or. El so semivocàlic /w/ davant de la vocal /o/ tendeix a emmudir-se o desaparèixer com en l'Appendix Probi n. 176 pavor, non paor ${ }^{16}$. També la documentació literària ens ajuda a interpretar i entendre aquest supernomen. Per exemple, Marcial -font que coincideix cronològicament amb la datació dels vidres: $s$. I d.C. $-{ }^{17}$ en un dels seus epigrames dedicats a l'auriga Scorpus diu plange, Favor, saeva pectora nuda manu, personificant el brugit, l'aplaudiment que se sentia en el circ quan se celebraven les curses, juntament amb la Victoria (vers 1), l'Honor (vers 3) i la Gloria (vers 4) noms tres dels quals són molt usats en l'onomàstica circenca tant per animals com per a éssers humans. També l'expressió plausus Romae (Epigr. X, 53, 2 del mateix autor) dirigida en aquest poema a un ésser humà i no pas a un cavall, contribueix a mostrar-nos l'ambient contextual del tipus d'apel-latius carinyosos usats en els jocs. Favor és semblant a noms com FAMOSUS $^{18}$-encara que sigui el nom d'un cavall- o VICTOR, nom utilitzat igualment per a cavalls ${ }^{19}$, aurigues ${ }^{20}$, esclaus ${ }^{21}$, etcètera.

La posició de la inscripció, la col-locació dels noms en la part superior del registre segon sobre les possibles figures de la imatge, és un

del nord d'Africa. K. M. D. Dunbabin, The mosaics of Roman North Africa, Oxford, 1978, pág. 94, 267. A més, per als noms de cavalls sempre es bo consultar les notes del treball de L. Salomonson, La mosaíque aux chevaux de l'antiquarium de Carthage, La Haya, 1965: i l'article de J. M. C. ToYNBEE, "Beasts and their names in the roman Empire", Papers of the British School at Rome, 1948, pág. 24 i ss

${ }_{15}$ Vas de l'antiga collecció Charvet de París, Morin-Jean, op. cit., págs. 190-191, n. I, amb més bibliografia sobre el tema. També mirar més amunt nota 8 .

${ }^{16} \mathrm{P}$. MonTEIL, Elements de phonetique et de morphologie du latin, Dijon, 1984, pág. 70. V. VANÄEN, Introducción al latín vulgar, Madrid, 1982 (traducció de Introduction au latin vulgaire, Paris, 1967), págs. 93-94. També: PIERnavieja, op. cit., n. 12

17 Marcial, Epigr. X, 50, 1-4; de: Marcial. Epigramas selectos (a cura de M. Dolç), Barcelona, 1964, n. LXV: Frangant Idumaeas tristis Victoria palmas; plange, Favor, saeva pectora nuda manu; mutet Honor cultus, et inquis munera flamis mitte coronatas, Gloria maesta, comas. MARCIAL, Epigr. X, 53, 2; també Piernavieja en parla.

${ }_{18}$ Testimoniat en el mosaic circenc de Barcelona: ClL II 5129. A. BALIL, "Mosaicos circenses de Barcelona y Gerona", Boletín de la Real Academia de la Historia, vol. CLI, (1962), pág. 257-351 i X. BARRAL, "Unes pintures murals romanes inèdites $\mathrm{i}$ el mosaic amb curses de circ de Barcelona", Quaderns d'Arqueologia i d'Història de la ciutat, vol. 15, (1973), págs. 36-68, ambdos amb més bibliografia.

${ }^{19}$ Com a nom de cavall surt en quatre defixiones de Susa: AudOLLNT, op. cit., n. 276, 278, 282 i 283; també en una inscripció de Roma, en una lluerna de terra cuita, etcètera.

${ }^{20}$ En un mosaic de Trier: KREnCKER-KRüBER, Die Trierer Kaiserthermen, 1959, págs $41-43$ i ss., lam. 56,57 i 58.

${ }^{21}$ Esclau que serveix vi a la casa de Fructus de Oudna, DunBaBin, op. cit., pág. 266. 
element desiciu $\mathrm{i}$ indefugible per a determinar que es tracta de noms de gladiadors i no de cavalls.

$\mathrm{Hi}$ ha més discusions per a resoldre el contingut de les inscripcions que es troben en els vasos circencs on la imatge representa els aurigues $i$ les quatre quadrigues; aquests són, per exemple, el de Colchester, $\mathrm{Na}$ mur (fig. 5) i el nostre fagment d'Empúries, malauradament tant fragmentat. En tots aquests vasos s'utilitza la mateixa fórmula: el nom propi freqüentment en vocatiu més la forma abreujada $V A$, possiblement vade o vale, com a exclamació animadora dirigida cap a l'arena del circ ${ }^{22}$.

-INNCITATEVA ICAREVA- del vidre d'Empúries fou interpretat, en un primer moment per Almagro ${ }^{23}$ i seguit per Piernavieja, com: VICIT ATEVA i ICAREV, pensant que aquests dos noms eren del funalis de l'esquerra de cada quadriga. En el primer fragment del vidre es pot veure com el darrer tras de la primera lletra que queda tallada, és absolutament vertical, éssent el primer una línia en diagonal: \! , corresponent millor a una $\mathrm{N}$, per la relació d'aquesta amb les altres lletres, i no a una $\mathrm{V}$ com pensaren en un principi. Així doncs tenint NCITATEVA només resta afegir la I inicial del nom INCITATUS (en aquesta inscripció en vocatiu), nombrosament testimoniat tant a la literatura (Marcial Epigr. $X, 76,9$ ), com a l'epigrafia (C/L XV, 6253-6261, amb els cavalls ASTRAGALA i AQUILUS); en aquests dos testimonis el nom fa referència a un auriga. També el cavall de Calígula duia aquest nom (Suetoni, Cal. 55).

ICARUS - el segon nom d'aquest fragment, també en vocatiu- només és testimoniat com a nom de cavall, en el mosàic de cacera i en el mosàic del vaixell ${ }^{24}$ d'Althiburos (Medeina) Tunísia. En aquest cas podem observar l'utilització de noms tant per homes com per animals, fenòmen que s'acostuma a trobar en l'onomàstica circenca. Hi ha força apel-latius circencs testimoniats tant per a cavalls com per a aurigues. Passa el mateix, gairebé, amb l'auriga POLISTE(F)ANUS del mosàic de Via Imperiale de Roma ${ }^{25}$ els dos paral-lels que hi ha en mosàic es refereixen a

n. 4, pág. 123. També està testimoniat com a nom de lleopard en el mosaic de Magerius de Smirat (Dunbabin, op. cit., pág. 268, Smirat n. 1).

${ }_{22}$ Com es pot veure en la figura 5 .

${ }^{23}$ Almagro, op. cit., 1952, n. 156 i 153.

${ }^{24}$ M. Ennaifer, La cité d'Althiboros, Tunísia, 1976, estudia els dos mosaics i en la pàgina 120 i ss. dóna un llistat dels noms de cavalls i gossos que hi apareixen.

${ }^{25}$ L. AvettA, "Roma. Via Imperiale", Tituli, 3, 1985, pág. 54. 

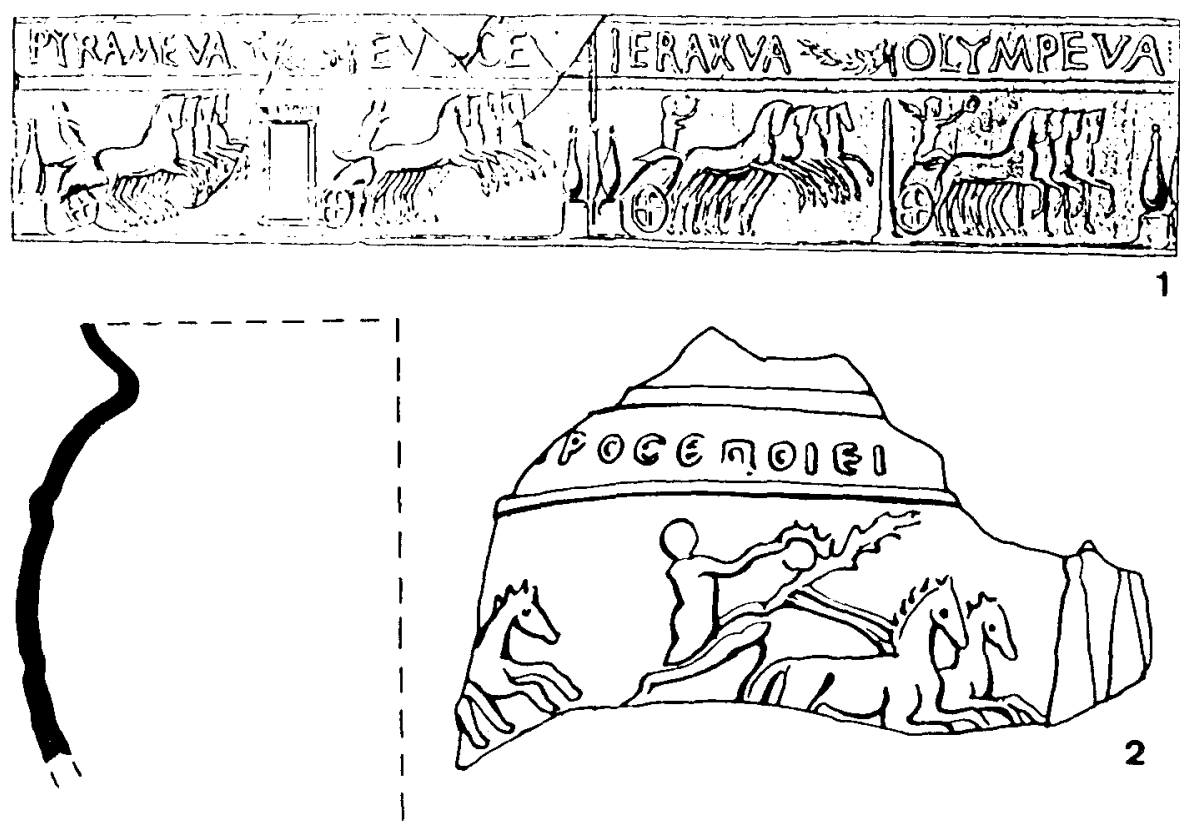

Figura 5. 1, Couven (Museu de Namur) (segons A. Kisa, 1908); 2, Egipte? (Col.leció J. Barrelet, Paris) (segons D. B. Harden, 1982). 
cavalls circencs, un en el mosàic circenc de Bell-lloc (Girona) ${ }^{26}$ i l'altre en el mosàic de la coronació de Venus d'Ellès ${ }^{27}$. S'usaven indistintament uns per altres. Encara que n'hi hagi alguns que guardin un caràcter d'exclusivitat. Tema, però, massa ampli per a tractar-lo en aquestes línies.

Pel que fa al formulari utilitzat en aquest vidre, trobem força testimonis que ens ajuden a entendre la nostre inscripció. En un vidre de Colchester llegim: HIERAXVA OLYMPAEVA ANTILOCEVA CRESCESAV (fig. 4,1 ); $i$ en un de Namur: PYRAMEVA EU[++ CEE[va] (h) IERAXVA $O L Y M P E V A$. La forma $V A$ només canvia per $A V$ en el primer vidre CRESCESAV. En aquest cas sembla que sigui la forma d'indicar el vencedor de la cursa o el favorit dient $A V(e)$, saludant, com mostra Marcial en lam, iam tu prior es, Naevole, vincis: ave (Epigr. III, 95, 14) ${ }^{28}$.

L'abreujament VA ha estat interpretat de dues maneres, com vade o vale, ambdues no es diferencien massa en el seu contingut. Els dos desenvolupaments expressen la mateixa exclamació que reflecteix els crits d'ànim dels espectadors en el circ en vers la quadriga que corre o ha corregut cap a la meta. Aquesta expressió acompanyada per un nom, el de l'auriga o el del cavall, o els dels dos, simbolitza tota l'acte "exaltat" d'un espectador-seguidor "adepte" a les curses de circ quan està en la grada i anima a la seva factio. El material en el qual es troben testimoniats els noms és una font més de documentació, ens mostra una realitat molt especifica d'un moment històric concret. En tant que una anàlisi sociologica. els vidres amb relleu, com els mosàics, elements de luxe, ens transmeten la devoció pels jocs d'una classe social alta i enriquida de la vida romana de principis de l'Imperi.

Normalment la forma abreujada $V A$ només la trobem en vidres $\mathrm{i}$ en contorniats. La tenim testimoniada acompanyada de noms en nominatiu o vocatiu o amb noms en ablatiu. El més freqüent és trobar-la precedida d'un nom en nominatiu o en vocatiu el qual correspon al de l'auriga: l'exemple més clar el trobem en una peça de marbre publicada per Steiner ${ }^{29}$ on hi ha un cavall representat i sobre hi ha la inscripció AVRA, essent aquest el nom de dita euga; separat per una línia posa AUSPI-

A. Balil, op. cit., pág. 333; i M. DARDER, “Els noms de cavalls i d'aurigues al mosaic de la Torre de Bell-lloc (Girona): paral-lels a l'imperi romà". Fonaments (en premsa, 1988).

27 Entre altres, Dunbabin, op. cit, pág. 102 i 261.

${ }^{28}$ M. Valerii Maritalis epigrammaton libri, (ed. i corr. per I. Borovskij, Teubner), Leipzig. 1976. A. KISA, Das Glass im Altertume, vol. II i III, Leipzig, 1908, pág. 967 i n. 307.

${ }^{29}$ En l'article, curt però densissim, de M. Bos, "Spielsteine als Rennpterde» op. cit., I 

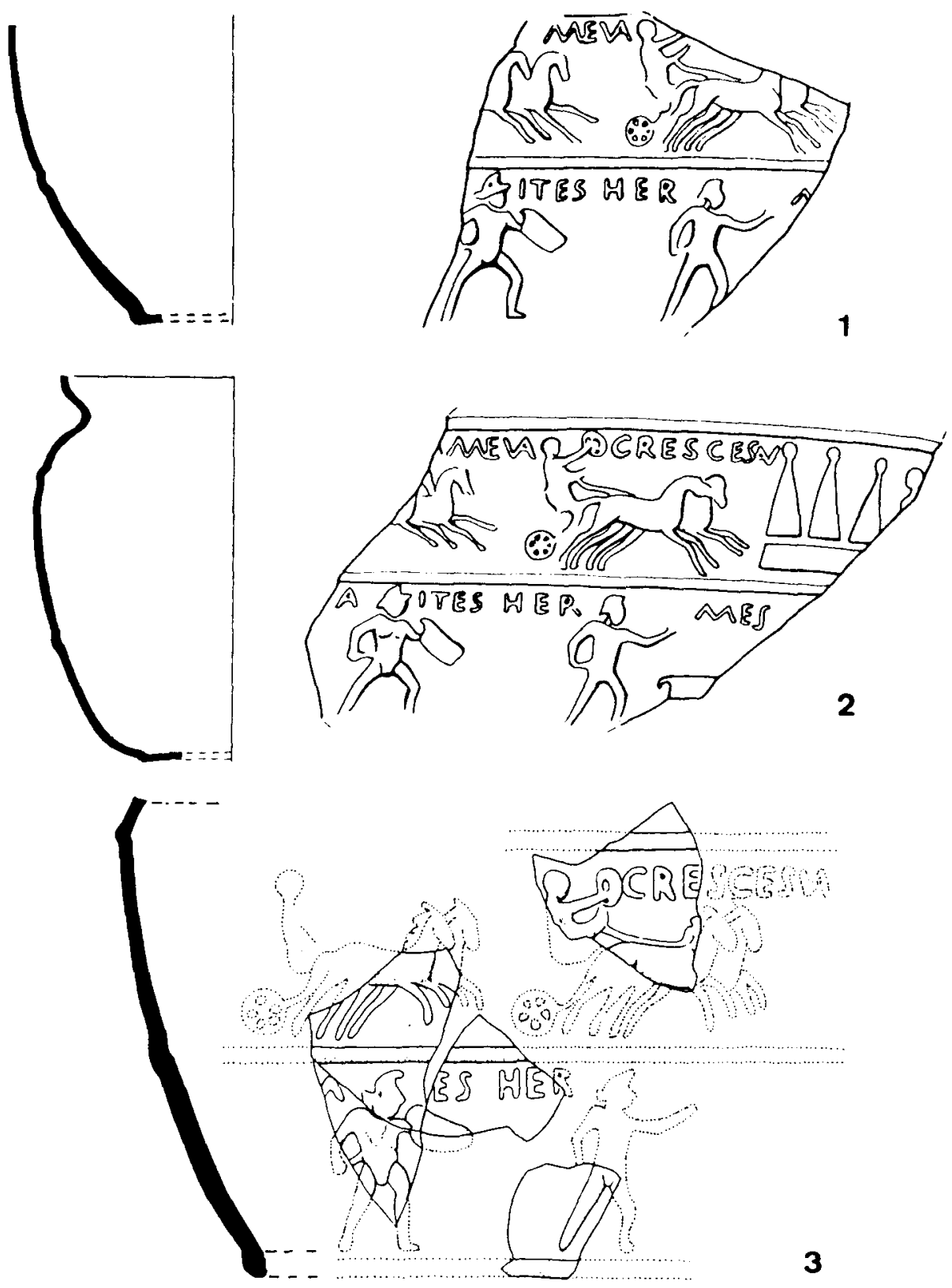

Figura 6. 1, Southwark (Londres); 2, Harllip (Kent); 3, Oberwinterthur (Viturum, Suissa). (Segons D. B. Harden, 1982). 
Noms d'aurigues i de gladiadors en dos peces de vidre d'Empúries
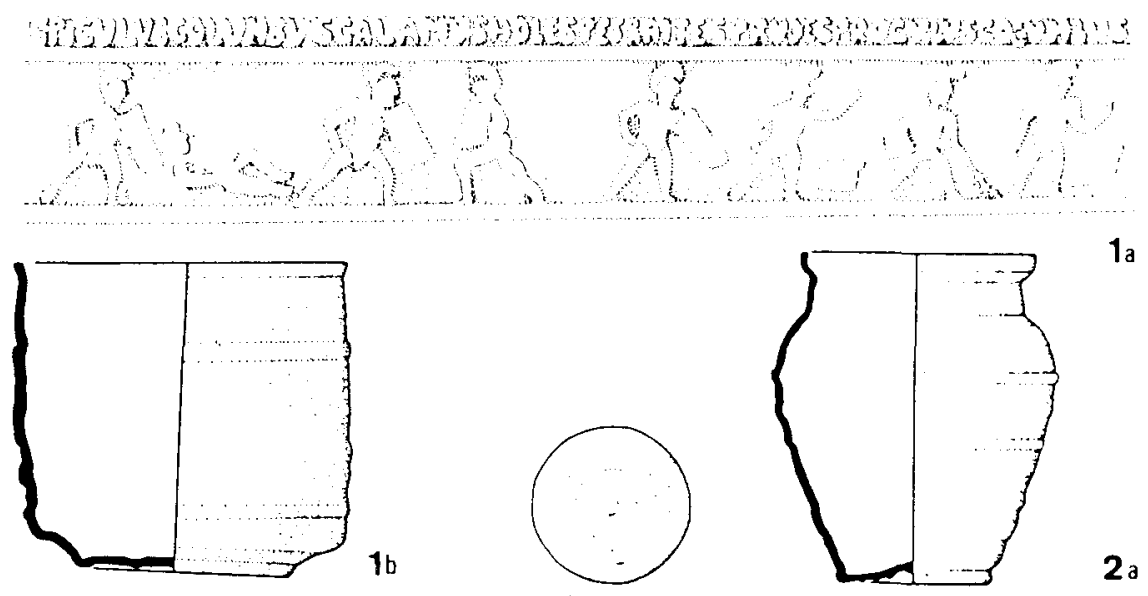

$1 \mathrm{a}$

2a
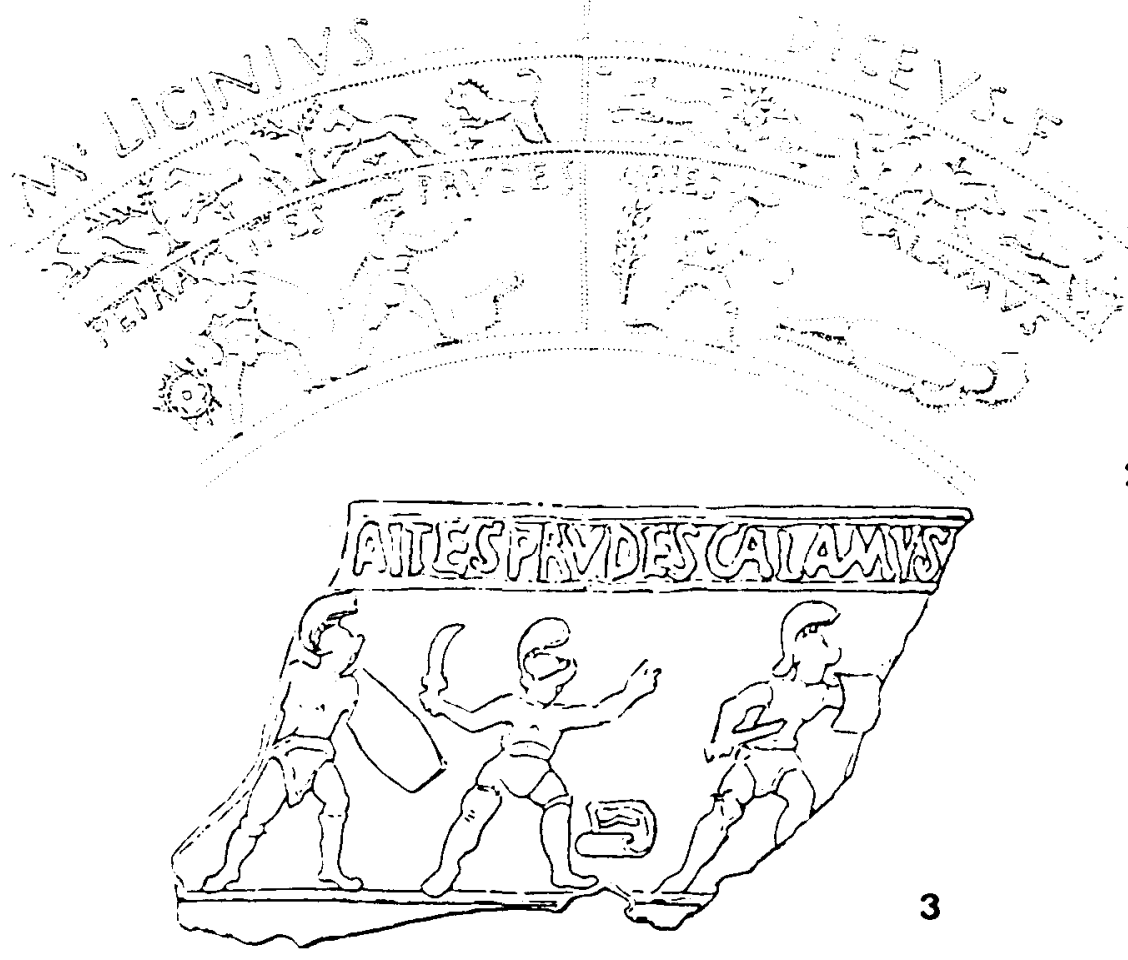

$2 \mathrm{~b}$

Figura 7. 1a-1b, Le Cormier (Chavagnes-en-Paillers, Vendée); 2a-2b, Sopron (Oedenburg, Hongria) (1 i 2 , segons D. B. Harden, 1987); 3, sense procedencia (Museu de Viena) (segons G. Ville, 1964). 
CIUS i separat per una altra línia, per sota també, es llegeix $V A$; de la col-locació del text dins de la rodona queda molt clar que AVSPICIVS VA no fa referència a l'equí representat sinó a l'auriga; a més, AVRORA tant pot estar en nominatiu com en ablatiu, fet que deixa marge per tal que, d'aquesta manera, el nom de l'euga - en ablatiu instrumental- sigui l'instrument a partir del qual l'auriga assoleixi la victòria.

$\mathrm{Si}$, en canvi, el nom es troba en ablatiu, aquest fa referència al cavall, al funalis de la factio en qüestió. Dos exemples comparatius que confirmen aquesta afirmació són: la inscripció $A Q U I L O V A$, en una tabella d'una lluerna que hi ha al Museu Britànic ${ }^{30}$, on hi ha un cavall amb un grup de seguidors i la inscripció d'un contorniat on es llegeix ASTURIUS $V A$ FORTUNIO IN SOLEM 8 IIS ${ }^{31}$. Són dues oracions el subjecte de les quals no és el cavall ja que el nom dels equi es troba en ablatiu instrumental. En aquests casos els cavalls són els «instruments» gràcies als quals l'acció de l'oració exclamativa es durà a terme o s'ha dut amb bon fi. L'exclamació, però, es dirigeix a un subjecte que participa com actor de l'acció: l'auriga, en aquest darrer exemple ASTVRIVS, o tots els seguidors de la factio, en el grup de la lluerna.

Aquests casos mostren com el formulari amb VA de les inscripcions estudiades fa referència al nom de l'auriga, ja que el nom que precedeix a l'exclamació abreujada està en cas nominatiu o vocatiu.

HERMES i FAVOR, gladiadors, i INICITATVS i ICARVS, aurigues, testimoniats en vidres d'Empúries del s. I d.C., augmenten el llistat onomàstic de noms $i$ apel-latius de personatges circencs, una nova font per a l'estudi i anàlisi de la realitat històrica romana.

en P. STEINER, "Römisches Brettspiel und Spielgerät aus Trier" Saalburg Jahrbuch, IX, (1939), pág. 34-45 i lam. 19-22, i a M. Rostovtezw, Römische Bleitesserae, 1905, (54 lám. 12 per a l'exemple anterior), es recullen nombrosos testimonis amb l'abreujament - $V A$.

30 A. KISA, op. cit., pág. 955: per a la inscripció AQVILO VA (CIL XV 6258) desenvolupa: vade feliciter; en canvi per al VA de la inscripció llarga del vidre diu: va(le), pág. 967 n. 307.

${ }^{31}$ M. Bós op. cit., pág. 179, interpreta ASTVRIVS com el nom del cavall i FORTUNIUS com el nom de l'auriga, dient que aquest últim va a guanyar el premi. Peró FORTUNIO està en ablatiu, no potser, com diu ell, qui realitza lacció del verb. 